\title{
NATECH HAZARD IDENTIFICATION AT NATIONAL LEVEL FOR SEVESO SITES AFFECTED BY FLOODS AND EARTHQUAKES
}

\author{
ZOLTÁN TÖRÖKa , ALEXANDRU OZUNU ${ }^{a, b}$ *, ANDREI RADOVICI ${ }^{a}$, \\ CRISTIAN MALOȘ ${ }^{a}$, ADRIANA CALAPOD ${ }^{a}$, FRANCISC SENZACONIc
}

\begin{abstract}
The intensity of disasters is on an upward trend and inhabited areas are expanding into various risk areas, threatened by natural, technological or complex multi-hazards. The present study focuses on the analysis of Seveso-type economic operators whose activity is regulated by Law 59/2016 on the control of major-accident hazards involving dangerous substances. In Romania, the natural hazards that can trigger technological accidents in these sites are largely represented by earthquakes and floods. The analysis presented in this study was performed for a recurrence period of 475 years for earthquakes and 500 years for floods. The results of the analysis highlighted the sites in Romania that present specific Natech risks. Also, the possible technological accidents that may occur as a result of the manifestation of natural hazards have been identified for each site while a more detailed analysis was performed for the selected processes based on qualitative criteria. Finally, a ranking of these sites for Natech risks is presented considering the two natural hazards.
\end{abstract}

Keywords: Natech, Seveso, earthquake, flood

\section{INTRODUCTION}

Although the Romanian chemical industry is no longer as well represented as before 1989 [1] there are a number of companies that still manage large quantities of hazardous substances [2]. In the context in which

\footnotetext{
a Babeş-Bolyai University, Faculty of Environmental Science and Engineering, ISUMADECIP Institute, 30 Fântânele str., RO-400294, Cluj-Napoca, Romania;

b Disaster Management Training and Education Centre for Africa (DiMTEC), University of the Free State, Bloemfontein, South Africa

c General Inspectorate for Emergency Situations, Ministry of Internal Affairs, Romania

*Corresponding author: alexandru.ozunu@ubbcluj.ro
} 
the intensity and complexity of disasters is on an upward trend [3]-[6] and inhabited areas are expanding into various risk areas, a reference point in terms of impact on the health of the population and the environment is represented by technological accidents [7]. It is this complex nature of disasters that has led to the study of Natural hazard triggered technological accidents (Natech) and multi-hazard events. Natechs involving the release of hazardous materials were studied for the first time at the end of the 1970s and were mainly focused on earthquakes as the main triggering event, only later they were focusing on other types of natural hazards such as floods [8]. The basic concept, which was later developed, refers to the natural hazards capacity to determine the loss of containment (LOC) in affected industrial facilities causing pollution, toxic dispersions, fires or explosions [9], [10].

Even though Natechs are low probability events, the linked consequences are significant enough to determine a comprehensive analysis which can fall outside traditional risk assessment and management practices [11]. An overview article on advances in Natech research [8], showed that the peer reviewed papers were grouped in three major categories based on the type of hazards (geological, hydrometeorological and multi-hazards) and referred to four stages in the risk management process: accident analysis and return of experiences, risk assessment, risk treatment/risk reduction, risk communication and risk perception.

Numerous examples of Natech disasters and their investigation, such as the Kocaeli earthquake in Turkey which destroyed the Tupras refinery [12], or the Tohoku earthquake and consequent tsunami in Japan causing multiple Natech disasters at the Fukushima nuclear plant, Chiba and Sendai refineries etc. [13] are presented in the scientific literature. Lessons learned from these disasters are key elements to consider in future risk mitigation strategies and plans.

A study developed by Campedel [14] of Natech accidents reported in the main chemical accident databases, such as ARIA, MARS, DFC, MHIDAS, NRC, FACTS etc., shows an average of 2-3\% of Natech events out of the total registered accidents. The author concludes that the very low number of these events is mostly due to the improper reporting of accident data in terms of causes and consequences. The results of the study reveal that in case of floods the most affected equipment were atmospheric storage tanks, floating roof storage tanks, pipelines and pressurized tanks, mostly involving the release of oil, diesel and gasoline and leading to water and ground contamination, fires or explosions. In case of earthquakes the most affected equipment were pipeworks and atmospheric storage tanks leading to releases followed by fire, explosion, dispersion and ground contamination [14]. 
The first disaster risk assessment at national level in Romania was conducted under the coordination of General Inspectorate for Emergency Situations (GIES) within the "RO-RISK" project and aimed both natural and anthropic related risks. Although the results of the project indicated a generally lower level of technological risks than that represented by earthquakes or floods [2], one of the conclusions was that the main direction of future research should be determined by a more detailed analysis of the interaction between natural and technological hazards [15].

In Romania the prevention and control of major industrial accidents involving dangerous substances is regulated by Law 59/2016 [16], being the Seveso III Directive of the EU Commission transposed into the national legislation. The law stipulates that in the risk analysis the possible internal and external events, such as natural hazards, must be considered as accident initiating factors [16].

The earthquake risk in Romania, determined by the Vrancea seismic region, is one of the highest in Europe and has caused many casualties and extensive damage in the past centuries. Natech risk analyses have been carried out for Romanian Seveso-type sites, such as the study conducted by Gheorghiu et.al for a petroleum product storage tank farm, within Vega refinery, affected by a possible seismic event [17], or the case study developed in "RO-RISK" project considering earthquake induced chlorine release from a storage tank, within Oltchim site [2]. The results of these studies have reflected an increase of the overall risk with one order of magnitude when considering the earthquake induced Natech events in the risk analysis, compared to pure technological risks [2], [18]. Due to the above presented aspects, a national level analysis of possible Natech accidents is with high importance.

In what follows, this study aims to provide an overview of the situation of Seveso operators from Romania, located in earthquake and flood prone areas and the possible outcomes of the interaction between natural and technological hazards. The study presents a starting point for the future national multi-risk assessments. A ranking of these sites have been made for both Natech types, based on qualitative criteria and expert judgement. The study presents a starting point for the future national multi-risk assessments.

\section{RESULTS AND DISCUSSION}

The results of the exposure analysis of Seveso sites to the flood hazard highlighted that a number of 20 sites, out of the total 245, are located in floodable areas where water depth can reach values that varies from 0.1 up to 11.2 meters for flood events with a recurrence period of 500 years (Figure 2). 


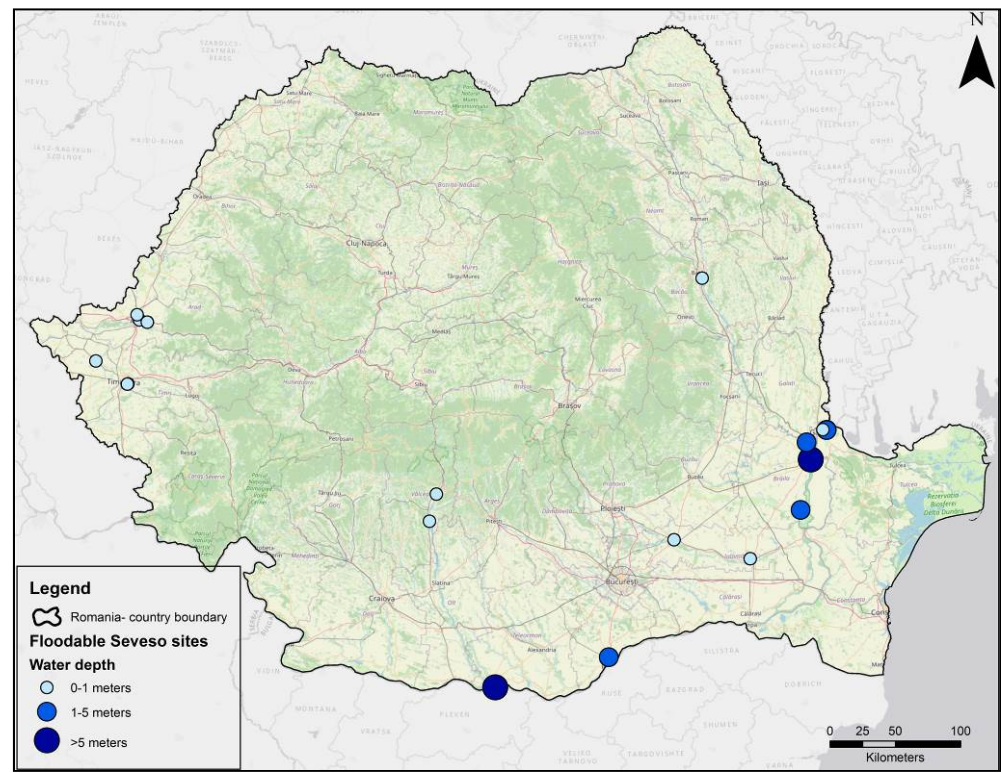

Figure 1. Seveso sites exposed to floods in Romania

From the point of view of activities carried out within these sites, it can be mentioned that 5 operators have petroleum products / fuel storage activities, followed by the compression and distribution of LPG and the production of technical gases. The other sites operate in the field of agriculture or production of fertilizer, vehicles and energy. The most common hazardous substances found on these sites, and in the largest quantities, are derived petroleum products like diesel oil, gasoline or naphtha stored in atmospheric or floating roof tanks, which are highly vulnerable to floods. Ammonium nitrate, its precursors and liquefied gases are the following hazardous materials when considering degree of occurrence and quantities stored within the sites. The information extracted from the hazard sheets specific to each of the operator, developed within RO-RISK Project, indicates the following types of possible events: toxic dispersions in air, fires, explosions and BLEVE. To these scenarios the water contamination can also be added as the main outcome of a release in case of floods.

The analysis regarding the number of Seveso sites located in earthquake prone areas highlighted a number of 4 active sites in zones with PGA values higher than $400 \mathrm{~cm} / \mathrm{s}^{2}$ and a number of 38 sites in areas with PGA values between $300-400 \mathrm{~cm} / \mathrm{s}^{2}$. 


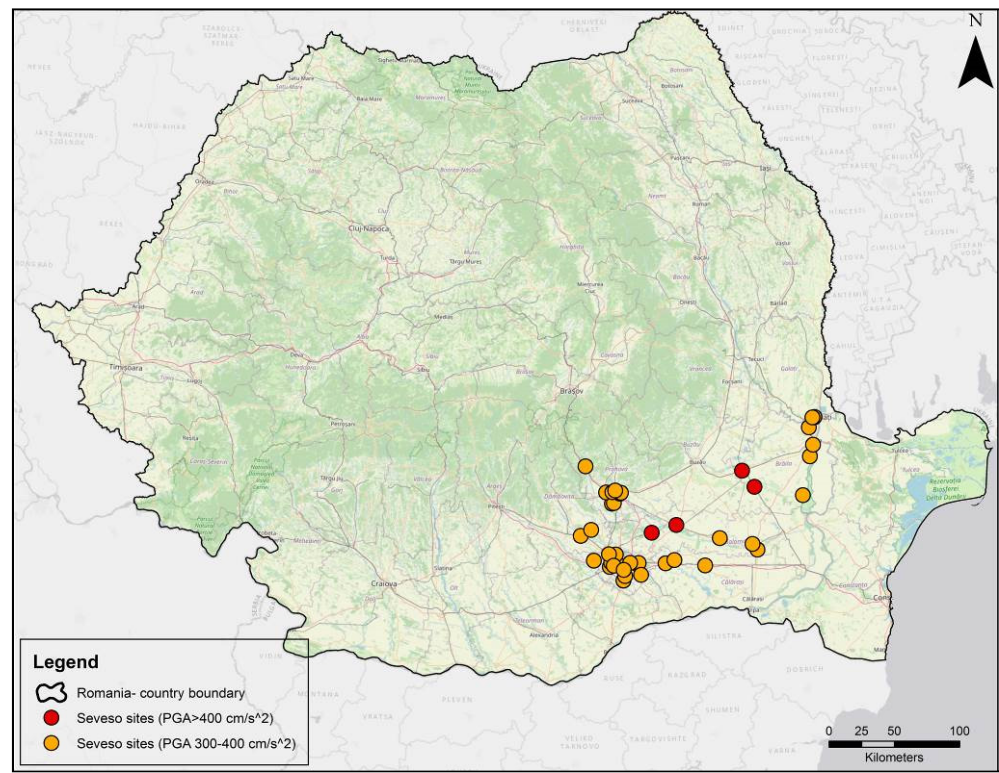

Figure 2. Seveso sites exposed to earthquakes in Romania (PGA $>300 \mathrm{~cm} / \mathrm{s}^{2}$, recurrence period-475 years)

Two of the sites located in the areas where PGA reach values higher than $400 \mathrm{~cm} / \mathrm{s}^{2}$ operates in the field of storage, compression and distribution of LPG, and the other two are involved in the storage activity of the fossil fuels. Thus, the substances present on these sites are mostly represented by liquid or liquefied gas fuels, the most probable scenarios can be fires, explosions, BLEVEs and ground contamination.

Regarding the field of activity of the sites located in area where PGA can reach values between $300-400 \mathrm{~cm} / \mathrm{s}^{2}$, the results of the analysis indicate that the largest number of these sites operate in the field of compression and distribution of LPG (6 sites) on par with storage of petroleum derived fuels. Significant activities of the operators are also found in the oil refining, energy production and agriculture sectors. As this area largely corresponds to the oil extraction fields in Romania, explains the fact that most operators carry out related activities and the most common hazardous substances at the sites are petroleum derivatives. The hazard sheets prepared for these sites indicate the possibility of four types of technological hazards: toxic dispersions, fires, explosions and BLEVEs, to which the ground contamination can be added.

The situation of the sites exposed to the two types of natural hazards analyzed, from the point of view of the worst-case scenarios for technological accidents, is presented in Table 1 . The values presented in the table refer only 
to the scenarios resulting from the inherent characteristics of the materials and processes, not being influenced by the possible action of natural hazards and further cascading events.

Table 1. The number of occurrences for possible worst-case scenarios in case of Natech accidents

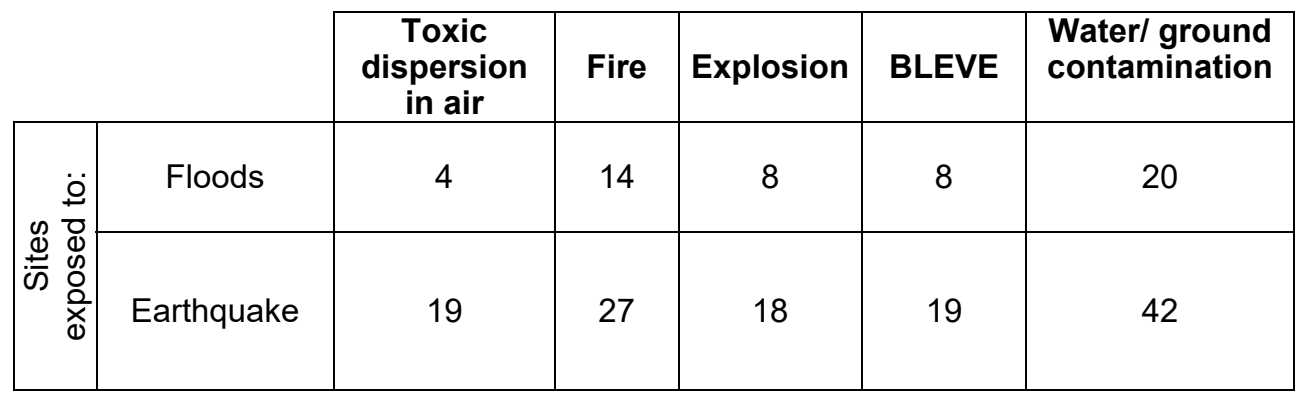

Using RO-RISK Project data, hazard and vulnerability identification and expert judgement a qualitative Natech ranking index of the sites has been calculated, based on the criteria evaluation described above.

The list of the top 5 sites for flood, respectively top 4 sites for earthquake induced Natech (presented only for PGA $>400 \mathrm{~cm} / \mathrm{s} 2$ ), are presented in Table 2.

Table 2. List of the top Natech prone sites from Romania

\begin{tabular}{|c|c|c|c|c|}
\hline Ranking & Flood & $\begin{array}{c}\text { Index } \\
\text { value }\end{array}$ & Earthquake & Index value \\
\hline $\mathbf{1}$ & $\begin{array}{c}\text { Donau Chem - } \\
\text { Teleorman county }\end{array}$ & 15 & $\begin{array}{c}\text { Romgaz - Prahova } \\
\text { county }\end{array}$ & 12 \\
\hline $\mathbf{2}$ & $\begin{array}{c}\text { Unicom Oil Terminal - } \\
\text { Galați county }\end{array}$ & 15 & $\begin{array}{c}\text { Conpet - Braila } \\
\text { county }\end{array}$ & 11 \\
\hline $\mathbf{3}$ & City Gas - Galați county & 10 & $\begin{array}{c}\text { Panebo Gaz - Braila } \\
\text { county }\end{array}$ & 9 \\
\hline $\mathbf{4}$ & $\begin{array}{c}\text { Padova Agricultura - } \\
\text { Brăila county }\end{array}$ & 10 & $\begin{array}{c}\text { Delta Gaz - lalomița } \\
\text { county }\end{array}$ & 9 \\
\hline $\mathbf{5}$ & $\begin{array}{c}\text { Air Liquide Romania - } \\
\text { Brăila county }\end{array}$ & 8 & & \\
\hline
\end{tabular}

It can be noticed that all sites from the Flood category are located in the immediate vicinity of the Danube river, which can produce high water levels in case of a 500 years flood event.

In case of the Earthquake category Romgaz site took the 1st place, because of the very high quantities of natural gas stored underground. Normally, in case of an earthquake, only damages at the pipeworks pipelines 
of the separate wells are expected with the release of much lower quantities of gas than the total stored. Therefore, a correction in the ranking is necessary, placing Conpet site in the top of the list.

\section{CONCLUSIONS}

The study aimed to create a rapid methodology for the ranking of Seveso-type chemical plants in Romania, from the perspective of Natech risks induced by floods and earthquakes.

A qualitative criteria evaluation was performed using RO-RISK project data combined with GIS technique. Among the limitations of the study, we can enumerate the lack of better resolution flood maps; the lack of flood water speed estimations and the qualitative way of Natech hazard identification and risk analysis.

In conclusion, this study is serving as a starting point for more detailed Natech risk assessments, using quantitative risk analysis methodologies. Furthermore, the importance of such studies in disaster risk reduction activities, land-use and emergency planning is highlighted due to the increased risk and complexity of Natech events.

\section{EXPERIMENTAL}

In order to determine which Seveso sites are located in flood and earthquake prone areas the list of the 300 operators analyzed within the national risk assessment [2] was verified and updated, aiming to identify the operators that still carry out their activity or are still under the provisions of Romanian Law 59/2016 [19].

The characterization of flood impact on equipment is based on frequency (recurrence period) and severity quantified by water depth and speed [14], [20].

The database on flood prone areas in our country, used within this study, was developed by the European Commission's Joint Research Centre (JRC) at global scale for flood events with 500-year recurrence period [21]. The limitations of this database are consisting mostly on spatial data resolution of approx. $1 \mathrm{~km}$ or 30 arcseconds and the fact that it is only available for large watercourses [22], [23] and representing only the water depth. Therefore, this study analyses the possible Natech events only from the perspective of the water depth, without quantifying the potential impact of floods on specific equipment.

Using Geographic Information System (GIS) specific techniques, the raster dataset was accessed in order to retrieve the values of water depth (in 
meters) characteristic for each cell. The data on Seveso sites located in floodable areas were obtained by overlapping the layer consisting in Seveso sites locations with the raster provided by JRC.

For the study of Seveso operators in earthquake prone areas, it was necessary to retrieve information related to the expected seismic effect, expressed in terms of earthquake ground-motion parameters. In this regard the peak ground acceleration (PGA) values calculated by Sokolov et al. [18] were used in order to identify the Seveso sites in high seismic prone areas. Again, the collocation information was obtained based on GIS techniques for areas with PGA higher than $300 \mathrm{~cm} / \mathrm{s}^{2}$ for events with a recurrence period of 475 year, this period being recommended in "Eurocode 8: Seismic design of buildings" and typically used in Natech risk assessments for Importance class II buildings, such as most of the Seveso establishments [3].

The schematic representation regarding the identification of the Seveso sites located in the area of manifestation of natural hazards can be consulted in Figure 1.

Along with the selection of sites that are located in flood prone areas or with high seismicity, specific data was extracted from safety reports or major accident prevention policies regarding the types and maximum quantities of substances possible to be present on sites, type of storage/processing and maximum distances calculated for the accident scenarios involving: fires, explosions, boiling liquid expanding vapor explosions (BLEVE), toxic dispersions in air or soil and water pollution.

Considering the above-mentioned data and the hazardous properties of the substances and their classification according with Annex 1 of Law 59/2016, ranking criteria were created for the following factors:

- Fire/explosion hazard: 1-low (P5c liquids, for ex. Crude oil); 2medium (P5b liquids - Gasoline etc., P3b aerosols); 3-high (P1a,b explosives, P2 flammable gases, P3a flammable aerosols, P5a flammable liquids);

- Pollution hazard: 1-low (without major environmental effects, harmful health hazards); 2-medium (E2 chronic environmental effects; H2 acute toxicity); 3-high (E1 acute environmental effects; $\mathrm{H} 1$ acute toxicity);

- Storage/processing vulnerability: 1-low (underground storage of natural gas; pressurized process equipment); 2-medium (pressurized storage in high quantities); 3-high (atmospheric storage in high quantities);

- Quantity: rounded value of the logarithm base 10 of the maximum quantity of substance possible to be present;

- Distance between first vulnerable elements dV (human settlements identified using GIS software) and radius of potential impact ri (calculated in the safety reports): 1-low (if $(\mathrm{dV}-\mathrm{ri})>100 \mathrm{~m}) ; 2$-medium (if $100 \mathrm{~m} \geq(\mathrm{dV}-$ ri) $\geq 0 \mathrm{~m}$ ); 3-high (if ( $\mathrm{dV}-$ ri) $<0 \mathrm{~m}$ ).

The total ranking score of each site is calculated by summing up the individual criteria scores. 
NATECH HAZARD IDENTIFICATION AT NATIONAL LEVEL FOR SEVESO SITES AFFECTED BY FLOODS AND EARTHQUAKES

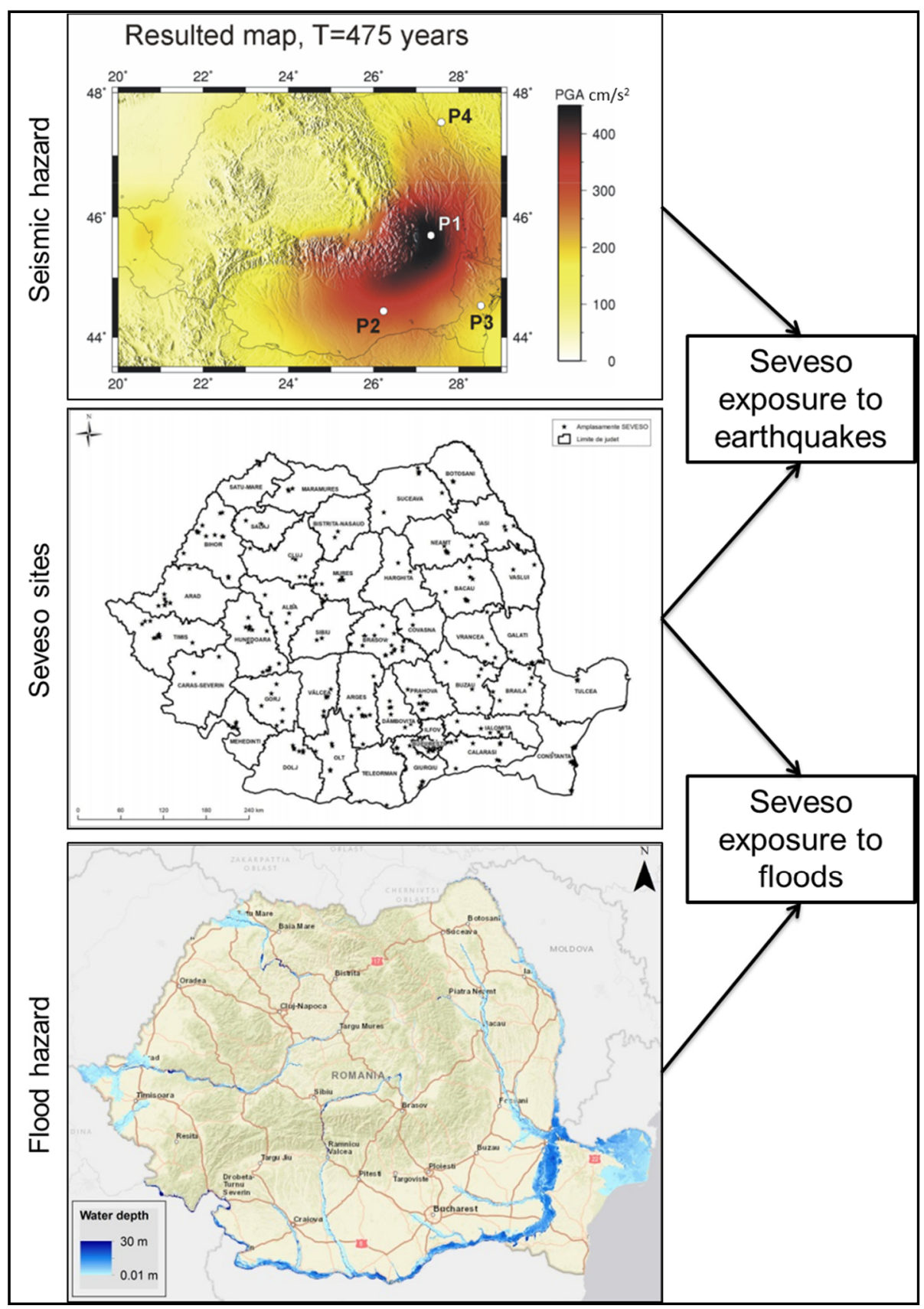

Figure 3. GIS workflow diagram for determining the exposure of Seveso sites to earthquakes [18] and floods [21] 
ZOLTÁN TÖRÖK, ALEXANDRU OZUNU, ANDREI RADOVICI, CRISTIAN MALOȘ,

ADRIANA CALAPOD, FRANCISC SENZACONI

\section{REFERENCES}

1. A. Ozunu; Safety hazards and risks in Romania. SSCHE Conference proceedings, 2019

2. Romanian General Inspectorate for Emergency Situations (IGSU); National Risk Assessment- Country Report, 2016

3. A.M. Cruz; L.J. Steinberg; A. Lisa; V. Arellano; J.-P. Nordvik; F. Pisano; State of the Art in Natech Risk Management (NATECH: Natural Hazard Triggering a Technological Disaster), 2004

4. M.K. Lindell; R.W. Perry; J. Hazard. Mater., 1996, 50, 31-46

5. K. Rasmussen; J. Hazard. Mater., 1995, 40, 43-54

6. H. Sengul; N. Santella; L.J. Steinberg; A.M. Cruz; Disasters, 2012, 36, 4, 723-743

7. A. Ozunu; Elemente de hazard şi risc în industrii poluante; Editura Accent, ClujNapoca, 2000, pp. 7-12

8. A.M. Cruz; M.C. Suarez-Paba; Prog. in Dis. Sci., 2019, 1, 100013, 1-4

9. J. Casal; Introduction. In Evaluation of the Effects and Consequences of Major Accidents in Industrial Plants, Elsevier Ltd., 2018, pp. 1-24

10. A. Mesa-Gómez; J. Casal; F. Muñoz; JLPPI, 2020, 64, 104071, 1-14

11. V. Cozzani; G. Antonioni; G. Landucci; A. Tugnoli; S. Bonvicini; G. Spadoni; JLPPI, 2014, 28, 10-22

12. S. Girgin; Nat. Hazards Earth Syst. Sci., 2011, 11, 4, 1129-1140

13. E. Krausmann; A.M. Cruz; Loss Prev. Bull., 2021, 277, 10-14

14. M. Campedel; Analysis of Major Industrial Accidents Triggered by Natural Events Reported in the Principal Available Chemical Accident Databases, JRC Publications Repository, Luxemburg, 2008, pp. 17-29

15. Romanian General Inspectorate for Emergency Situations (IGSU); Summary containing the conclusions of the study within component 1 of RO-RISK research, 2016, pp. 11-17

16. Law No. 59/2016 of 11 April 2016 on the control of major accident hazards involving dangerous substances; In Romanian Official Gazette no. 290, 2016

17. A.D. Gheorghiu; Z. Török; A. Ozunu; G. Antonioni; V. Cozzani; Chem. Eng. Trans., 2014, 36, 439-444

18. V.Y. Sokolov; F. Wenzel; R. Mohindra; Soil Dyn. Earthq. Eng., 2009, 29, 364-381

19. Romanian General Inspectorate for Emergency Situations (IGSU); List of economic operators classified in accordance with the provisions of Law 59/2016, 2019, Available at: https://www.igsu.ro/Resources/Seveso/Lista operatorilor economici clasificati in conformitate cu prevederile Legii 59_2016 la 30.12.2019 pentru site IGSU.doc

20. A.M. Cruz; N. Okada; Nat. Haz., 2008, 46, 2, 199-220

21. F. Dottori; L. Alfieri; P. Salamon; A. Bianchi; L. Feyen; F. Hirpa; Flood hazard map of the World - 500-year return period, Eur. Comm. Jt. Res. Cent. [Dataset], 2016

22. L. Alfieri; P. Salamon; A. Bianchi; J. Neal; P. Bates; L. Feyen; Hydrol. Process., 2014, 28, 13, 4067-4077

23. F. Dottori; P. Salamon; A. Bianchi; L. Alfieri; F.A. Hirpa; L. Feyen; Adv. Water Resour., 2016, 94, 87-102 